\title{
A nonparametric statistical technique for combining global precipitation datasets: development and hydrological evaluation over the Iberian Peninsula
}

\author{
Md Abul Ehsan Bhuiyan ${ }^{1}$, Efthymios I. Nikolopoulos ${ }^{1,2}$, Emmanouil N. Anagnostou ${ }^{1}$, Pere Quintana-Seguí ${ }^{3}$, and \\ Anaïs Barella-Ortiz ${ }^{3,4}$ \\ ${ }^{1}$ Department of Civil and Environmental Engineering, University of Connecticut, Storrs, CT, USA \\ ${ }^{2}$ Innovative Technologies Center S.A., Athens, Greece \\ ${ }^{3}$ Ebro Observatory, Ramon Llull University - CSIC, Roquetes (Tarragona), Spain \\ ${ }^{4}$ Castilla-La Mancha University, Toledo, Spain
}

Correspondence: Emmanouil N. Anagnostou (manos@uconn.edu)

Received: 6 May 2017 - Discussion started: 6 June 2017

Revised: 16 November 2017 - Accepted: 10 January 2018 - Published: 26 February 2018

\begin{abstract}
This study investigates the use of a nonparametric, tree-based model, quantile regression forests $(\mathrm{QRF})$, for combining multiple global precipitation datasets and characterizing the uncertainty of the combined product. We used the Iberian Peninsula as the study area, with a study period spanning 11 years (2000-2010). Inputs to the QRF model included three satellite precipitation products, CMORPH, PERSIANN, and 3B42 (V7); an atmospheric reanalysis precipitation and air temperature dataset; satellite-derived nearsurface daily soil moisture data; and a terrain elevation dataset. We calibrated the QRF model for two seasons and two terrain elevation categories and used it to generate ensemble for these conditions. Evaluation of the combined product was based on a high-resolution, ground-reference

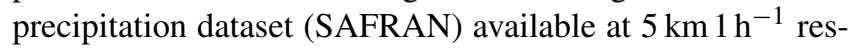
olution. Furthermore, to evaluate relative improvements and the overall impact of the combined product in hydrological response, we used the generated ensemble to force a distributed hydrological model (the SURFEX land surface model and the RAPID river routing scheme) and compared its streamflow simulation results with the corresponding simulations from the individual global precipitation and reference datasets. We concluded that the proposed technique could generate realizations that successfully encapsulate the reference precipitation and provide significant improvement in streamflow simulations, with reduction in systematic and random error on the order of $20-99$ and $44-88 \%$, respectively, when considering the ensemble mean.
\end{abstract}

\section{Introduction}

Accurate estimates of precipitation on a global scale, which are essential to hydrometeorological applications (Stephens and Kummerow, 2007), rely primarily on satellite-based observations and atmospheric reanalysis simulations. Although advancement in both satellite retrievals and reanalysis-based precipitation datasets has been continuous (Seyyedi et al., 2014; Dee et al., 2011; Huffman et al., 2007; Mo et al., 2012), they are still associated with several sources of error (Derin et al., 2016; Mei et al., 2014; Seyyedi et al., 2014; Gottschalck et al., 2005; Peña-Arancibia et al., 2013) that limit their use in water resource applications. Quantifying and correcting the sources of the error and characterizing its propagation are important for improving and promoting the use of satellite and reanalysis precipitation estimates in hydrological applications on a global scale.

During the past two decades, research investigations have focused on characterizing the error in satellite precipitation products and its propagation in streamflow simulations (Hossain and Anagnostou, 2004; Li et al., 2009; Bitew and Gebremichael, 2011; Nikolopoulos et al., 2013; Mei et al., 2016). These studies have highlighted the dependence of the error on a multitude of factors, including seasonality, topography, soil wetness, and vegetation cover (Derin et al., 2016; Mei et al., 2014; Seyyedi et al., 2014; Hou et al., 2014). Other studies have used stochastic satellite rainfall error models to investigate uncertainty characteristics and their depen- 
dencies (Hossain and Anagnostou, 2006; Teo and Grimes, 2007; Maggioni et al., 2014; Adler et al., 2001; AghaKouchak et al., 2009) and have used stochastically generated ensemble rainfall fields as input in hydrological models to study the satellite precipitation uncertainty propagation in the simulation of various hydrological variables. The twodimensional satellite rainfall error model, SREM2-D (Hossain et al., 2006), has been used to evaluate the significance of surface soil moisture (Seyyedi et al., 2014) and seasonality (Maggioni et al., 2017) in modeling the error structure of satellite rainfall products.

Given the multidimensionality of error dependence and the lack of a clear winner among the various precipitation datasets established by these studies, we argue that, to mitigate the errors and uncertainties, one should combine the different precipitation datasets, taking into account the different climatological and land surface factors. A promising approach to modeling appears to be the application of statistical nonparametric techniques, which efficiently combine information on several factors (Ciach et al., 2007; Gebremichael et al., 2011). In fact, although nonparametric statistical techniques are not widely used in rainfall estimation, some notable examples exist in the literature, with encouraging results. Ciach et al. (2007) established a nonparametric estimation technique based on weather radar data to characterize the uncertainties in radar precipitation estimates as a function of range, temporal scale, and season. Lakhankar et al. (2009) introduced a nonparametric technique to retrieve soil moisture from satellite remote sensing products in reliable ways with sufficient accuracy. Moreover, Gebremichael et al. (2011) developed a nonparametric technique for satellite rainfall error modeling using rain-gauge-adjusted, ground-based radar rainfall and reported improved satellite precipitation performance with relatively large variation at low and high rainfall rates.

The use of nonparametric statistical techniques in error modeling has also gained popularity in weather forecasting, climate change prediction, and the modeling of hydrological processes (Croley, 2003; Brown et al., 2010; Mujumdar et al., 2008; Yenigun et al., 2013). Recently, a wide variety of nonparametric techniques have been developed for error analytics (Taillardat et al., 2016; He et al., 2017). Nonparametric statistical techniques require fewer assumptions for the form of the relationship and data. The advantages over parametric techniques for prediction are explained in detail in Guikema et al. (2010). Specifically, the authors exhibited better results (lower prediction error) with nonparametric techniques than with parametric analysis models. The techniques they used were classification and regression trees (CART) and Bayesian additive regression trees (BART) (Chipman et al., 2010). Another nonparametric technique, random forest (RF) regression, which provides information about the full conditional distribution of the response variable, was used by Breiman (2001) and found to yield more robust predictions by stretching the use of the training data partition.
This paper investigates the use of a nonparametric statistical technique for optimally combining globally available precipitation sources from satellite and reanalysis products. Specifically, we use the quantile regression forests (QRF) tree-based regression model (Meinshausen, 2006) to combine dynamic (for example, temperature and soil moisture) and static (for example, elevation) land surface variables with multiple global precipitation sources to stochastically generate improved precipitation ensemble. The proposed framework provides a consistent formalism for optimally combining several rainfall products by using information from these datasets. It is, furthermore, able to characterize uncertainty through the ensemble representation of the combined precipitation product. We present the development of the proposed framework and evaluate relative improvements in the combined rainfall product in detail. We also evaluate the new combined product in terms of hydrological simulations to assess the importance of precipitation improvement for streamflow simulations, thus highlighting the usefulness of this approach for global hydrological applications.

The paper is structured as follows: Sect. 2 briefly explains the study area and the datasets used. Section 3 describes the QRF model, the rainfall error analysis, and the hydrological model setup. Performance evaluation of the combined product in precipitation and corresponding hydrological simulations is presented in Sect. 4. Conclusions and recommendations are discussed in Sect. 5.

\section{Study area and data}

The study area we selected for this investigation is the Iberian Peninsula, which has three main climatic zones: Mediterranean, oceanic, and semiarid. The peninsula's climate is primarily Mediterranean, except in its northern and southern parts, which are characterized mostly as oceanic and semiarid, respectively. The topography varies from almost zero elevation to altitudes of $3500 \mathrm{~m}$ in the Pyrenees. For the hydrological analysis, we focused the study over the Ebro River basin and, specifically, on five subbasins of different spatial scale: (1) the Ebro River at Tortosa $\left(84230 \mathrm{~km}^{2}\right)$; (2) the Ebro River at Zaragoza $\left(40434 \mathrm{~km}^{2}\right)$; (3) the Cinca River at Fraga $\left(9612 \mathrm{~km}^{2}\right)$; (4) the Segre River at Lleida $\left(11369 \mathrm{~km}^{2}\right)$; and (5) the Jalon River at Grisen $\left(9694 \mathrm{~km}^{2}\right)$ (Fig. 1). The datasets we used are described below.

\subsection{Reference precipitation (SAFRAN)}

The default reference dataset was recently created by Quintana-Seguí et al. $(2016,2017)$ using the SAFRAN meteorological analysis system (Durand et al., 1993), which is the same as the one used in earlier studies over France (Quintana-Seguí et al., 2008; Vidal et al., 2010). SAFRAN uses optimal interpolation to combine the outputs of a meteorological model and all available observations, which in 


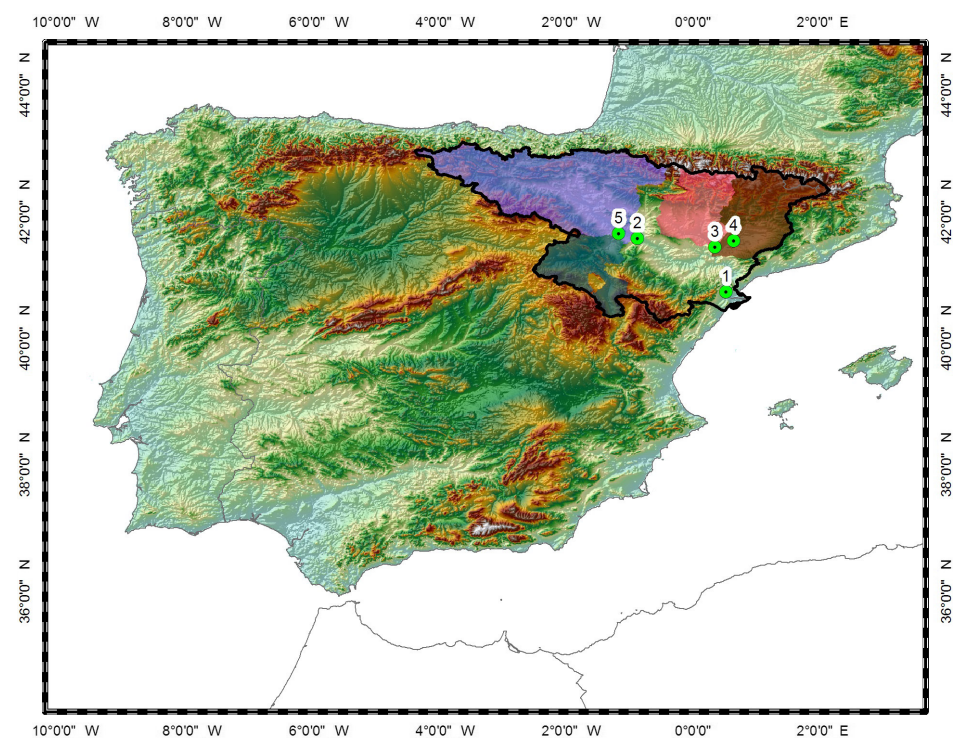

Figure 1. Map of the Iberian Peninsula case study area.

this case were provided by the Spanish State Meteorological Agency (AEMET). The variables analyzed were precipitation, temperature, relative humidity, wind speed, and cloudiness. In the case of precipitation, the first guess was deduced from the observations themselves instead of coming from a numerical model, like the other variables. The observations were analyzed daily (as opposed to every $6 \mathrm{~h}$ for the other variables), but the resulting product had a time resolution of $1 \mathrm{~h}$. This was achieved by an interpolation method that used relative humidity to distribute precipitation throughout the day. Spatially, the outputs are presented on a regular grid with $5 \mathrm{~km}$ resolution. The dataset (Quintana-Seguí et al., 2016), which spans 35 years, covers mainland Spain and the Balearic Islands.

\subsection{Satellite-based precipitation}

We used three gauge-adjusted quasi-global satellite precipitation products - CMORPH, PERSIANN, and 3B42 (V7) - in this study. CMORPH (Climate Prediction Center Morphing technique of the National Oceanic and Atmospheric Administration, or NOAA) is a global precipitation product based on passive microwave (PMW) satellite precipitation fields spatially propagated by motion vectors calculated from infrared (IR) data (Joyce et al., 2004). PERSIANN (Precipitation Estimation from Remotely Sensed Information using Artificial Neural Networks) is IR-based and uses a neutral network technique to connect IR observations to PMW rainfall estimates (Sorooshian et al., 2000). TMPA (Tropical Rainfall Measuring Mission Multisatellite Precipitation Analysis), or 3B42 (V7), is a merged IR and passive microwave precipitation product from NASA that is gaugeadjusted and available in both near-real time and post-real time (Huffman et al., 2010). Spatial and temporal resolutions of the satellite precipitation products are $0.25^{\circ}$ and 3-hourly time intervals, respectively.

\subsection{Atmospheric reanalysis}

For meteorological forcing, we selected the WATCH1 (Water and Global Change FP7 project) Forcing Dataset ERAInterim (hereafter WFDEI) (Weedon et al., 2014), a contemporary state-of-the-art database. WFDEI, a dataset that follows up on the European Union's WATCH project (Harding et al., 2011), is built on the ECMWF ERA-Interim reanalysis (Dee et al., 2011) with a geographical resolution of $0.5^{\circ} \times 0.5^{\circ}$ and a sequential frequency of $3 \mathrm{~h}$ for the time span 1979-2012, with particular bias corrections using gridded monitoring. Finally, we chose two atmospheric products (atmospheric precipitation and air temperature) among WFDEI variables as predictors for the nonparametric statistical technique.

\subsection{Soil moisture}

The soil moisture information used in this study was obtained from the satellite-based soil moisture estimates produced by the European Space Agency (ESA) Climate Change Initiative $(\mathrm{CCI})$ project under the ESA Programme on Global Monitoring of Essential Climate Variables (ECV) (Liu et al., 2011; Owe et al., 2008; De Jeu, 2003; http://www. esa-soilmoisture-cci.org/node/145). The ESA CCI (v02.0) soil moisture product is derived from passive and active microwave satellite-based sensors (Liu et al., 2011, 2012; Wagner et al., 2012) and provides information on daily surface soil moisture at $0.25^{\circ}$ spatial resolution and quasi-global scale. 


\subsection{Terrain elevation}

The Shuttle Radar Topography Mission (SRTM) dataset included in this study has, in recent years, been one of the most extensively used publicly accessible terrain elevation datasets. Available at $\sim 90 \mathrm{~m}$ spatial resolution, it was obtained using $1^{\circ}$ digital elevation model (DEM) tiles from the US Geological Survey and interpolated to the $0.25^{\circ}$ grid resolution to match the resolution of precipitation and soil moisture products.

\section{Methodology}

\subsection{Blending technique}

In this study, we applied a nonparametric, tree-based regression model, quantile regression forests (QRF) (Meinshausen, 2006), to produce a rainfall ensemble with respect to the reference precipitation. The model input includes the three global satellite precipitation datasets (CMORPH, PERSIANN, and 3B42-V7), the global reanalysis rainfall and air temperature datasets, and the satellite near-surface soil moisture and terrain elevation datasets, described in the previous section. The atmospheric products were interpolated in space using the nearest neighbor interpolation technique to match the resolution of precipitation satellite precipitation datasets. The spatial and temporal resolutions of the atmospheric products are $0.25^{\circ}$ and 3-hourly time intervals, correspondingly. The high-resolution SAFRAN data were matched to the satellite precipitation datasets on a pixel-by-pixel basis by averaging all high-resolution pixels within a $0.25^{\circ}$ pixel. Finally, all 3-hourly data were mapped to the grid resolution of $0.25^{\circ}$ chosen to be the final spatial resolution for the combined product.

QRF is derived from random forest regression (Meinshausen, 2006), which is capable of handling data from large samples; it has desirable built-in features, such as variable selection, interaction detection, incorporation of missing data, and the ability to save the trained model for future prediction (Nateghi et al., 2014). QRF uses a bagged version (bootstrapped aggregating) of decision trees by randomly sampling from the bootstrapped sample, which reduces variance and helps to avoid overfitting that improves the stability and accuracy of the algorithm (Meinshausen, 2006). QRF provides a nonparametric way to evaluate conditional quantiles for high-dimensional predictors of variables. The conditional distribution function of $Y$ is defined by

$$
\hat{F}(y \mid X=x)=P(Y \leq y \mid X=x)=E\left(1_{\{Y \leq y\}} \mid X=x\right),
$$

where $Y$ refers to observations of the response variable, $X$ is a covariate or predictor variable, and $E$ is the conditional mean, $E\left(1_{\{Y \leq y\}} \mid X=x\right)$, which is approximated by the weighted mean over the observation of $1_{\{Y \leq y\}}$ (Meinshausen, 2006). Then Eq. (1) can be expressed as
$\hat{F}(y \mid X=x)=\sum_{i=1}^{n} \omega_{i}(x) 1_{\left\{Y_{i} \leq y\right\}}$,

where weight vector $\omega_{i}(x)=k^{-1} \sum_{i=1}^{k} \omega_{i}\left(x, \theta_{t}\right)$ using random forest regression; $k$ indicates the number of single trees $(t=1, \ldots, k)$; and each tree is built with an independent and identically distributed vector $\theta_{t}$ (Meinshausen, 2006).

This nonparametric technique utilizes the weighted average of all trees to compute the empirical distribution function. It keeps not only the mean but also all observation values in nodes and, building on this information, it calculates the conditional distribution. In this method, consistency of the empirical quantities is induced based on a large number of instances in terminal nodes. The overall framework of the QRF scheme is shown in Fig. 2. Higher number of trees reduces the variance of the model. So, increasing the number of trees in the ensemble will not have any impact on the bias of the model. Furthermore, a higher variance reduction can be achieved by decreasing the correlation between trees in the ensemble. Therefore, QRF utilizes the optimal number "mtry" (size of the random subset of predictors) for split point selection at each node. This approach introduces randomness in the ensemble to reduce the correlation between trees, which helps to avoid overfitting (Meinshausen, 2006). In this study we used the default value $(k=1000)$ (Meinshausen, 2006) throughout all simulations to create the empirical distribution at each grid cell and used the crossvalidation experiments (see next section) to demonstrate stability of the method.

Specifically, we initialized a random forest of 1000 trees for each terminal node of each of the classified dataset and calculated the $95 \%$ prediction intervals at each grid cell. QRF utilizes the same weights to calculate the empirical distribution function and a weighted average of all trees for the predicted expected response values to calculate the empirical distribution. To conduct the hydrological simulations in this study, we resampled from the empirical distribution function 20 times per grid cell to obtain "reference"-like rainfall ensemble members.

To build the rainfall error model, we grouped available rainfall estimates from all input datasets (three satellite and reanalysis) into three subsets: (1) all rainfall products that report rainfall greater than zero; (2) all rainfall products that report zero rainfall; and (3) at least one product that reports nonzero rainfall. We categorized each case into two seasons: the "warm season", which included data from May through October, and the "cold season", which included data from November through April. We then classified each season category into two levels based on two terrain elevation ranges: above (high) and below (low) 1000 ma.s.l. Finally, for each subset, we prepared four groups (warm-high, warm-low, cold-high, cold-low) for the error model. For each group, leave-one-pixel-out cross-validation is applied where each point in the statistics is not included in the calibra- 


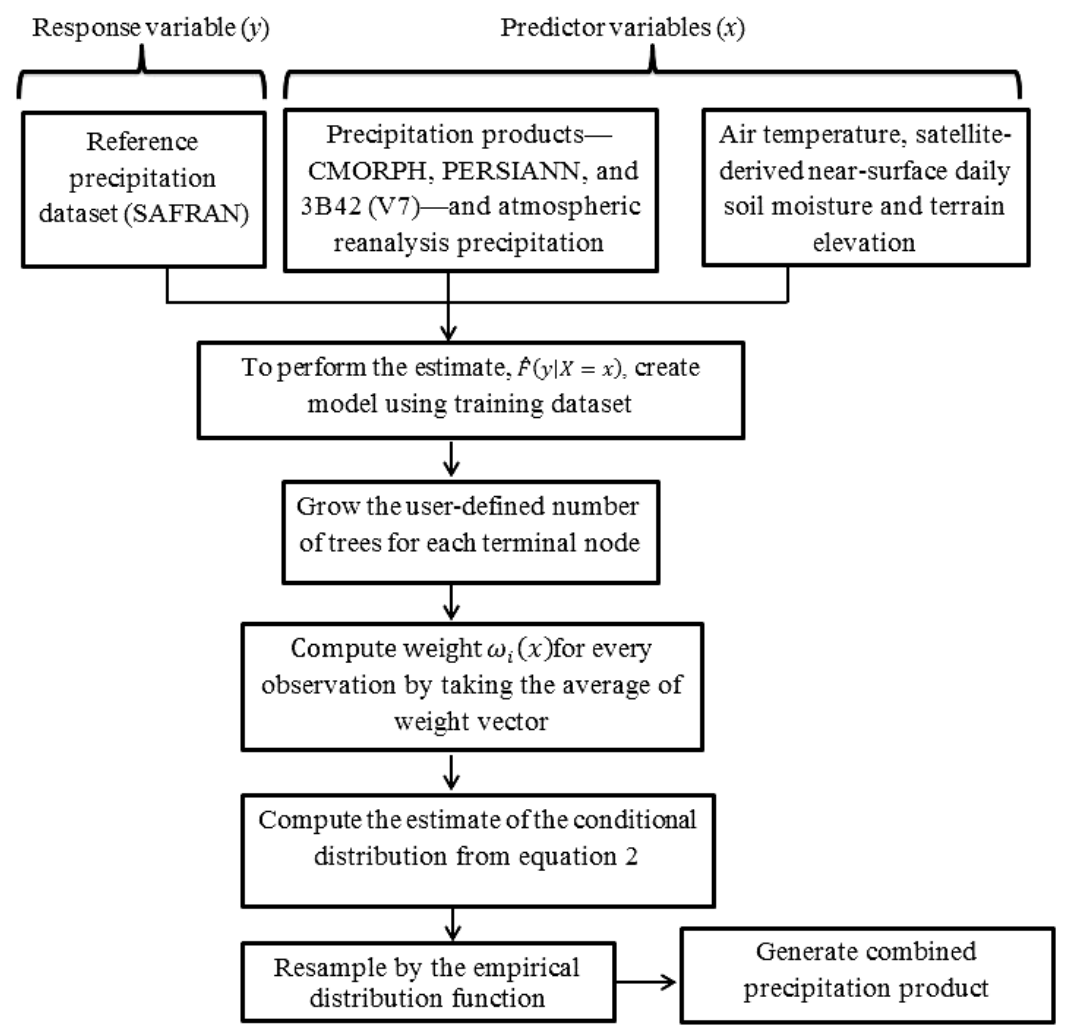

Figure 2. A schematic representation of the quantile regression forests (QRF) framework used.

tion of the technique. In general, prominent "mtry" is obtained by this method by extending the sample size and therefore preventing overfitting. Applying this validation method, the model exhibits great skill on both the training dataset and the unseen test data. Similarly, to strengthen the validation results, we also performed a test using leave-one-yearout cross-validation. Namely, for each year of the database hold out for validation, we calibrated on the rest of the years (10 years) and repeated the experiment for all 11 years of the study period. The model validation results based on leave-one-pixel-out and leave-one-year-out are described in Sect. 4.2.

\subsection{Hydrological modeling}

To perform the streamflow simulations, we used the SASER (SAfran-Surfex-Eaudyssée-Rapid) hydrological modeling suite. SASER is a physically based and distributed hydrological model for Spain based on SURFEX (Surface Externalisée), a land surface modeling platform developed by Météo-France (Masson et al., 2013) that integrates several schemes for different kinds of surfaces (natural, urban, lakes, and so on). The scheme for natural surfaces, ISBA (Noilhan and Planton, 1989; Noilhan and Mahfouf, 1996), has different versions, with differing degrees of complexity. Within SASER we used the explicit multilayer version (Boone,
2000; Decharme et al., 2011) with prescribed vegetation. The physiography was provided by the ECOCLIMAP dataset (Champeaux et al., 2005).

Since SURFEX has no river routing scheme, we chose the RAPID river routing scheme (David et al., 2011a, b) within the Eau-dyssée framework (http://www.geosciences.mines-paristech.fr/fr/equipes/ systemes-hydrologiques-et-reservoirs/projets/eau-dyssee). Eau-dyssée transfers SURFEX runoff (surface and subsurface or drainage) from the SURFEX grid cells to the river cells using its own isochrony algorithm. Then, RAPID uses a matrix-based version of the Muskingum method to calculate flow and volume of water for each reach of a river network. The current application of SASER uses HYDROSHEDS (Lehner et al., 2008) to describe the river network. As the current setup cannot simulate dams, canals, or irrigation, the resulting river flows are estimations of the natural system (that is, the system without direct human intervention in the form of irrigation or hydraulic infrastructure, such as dams or canals).

It is important to note that, since the current version of SASER uses the default parameters for its different schemes, it has not been specifically calibrated for the target basin. This has some implications. The benefit is that the model is not overfitted, which makes it directly comparable to global 
applications of SURFEX, which are not calibrated either. The downside is that the model might not perform optimally. In the future, we plan to improve the options used in the land surface model to adapt its structure better to the necessary physical processes that take place in the basin, while limiting the need for parameter calibration. For the purpose of this study, which involved the relative comparison of multiple rainfall forcing-based simulations, the current model setup was considered adequate.

\subsection{Metrics of model performance evaluation}

We based quantification of the systematic and random error of model-generated ensemble on different error metrics. We evaluated the random error component based on the normalized centered root mean square error (NCRMSE), which is defined as

$\mathrm{NCRMSE}=\frac{\sqrt{\frac{1}{n} \sum_{i=1}^{n}\left[\hat{y}_{i}-y_{i}-\frac{1}{n} \sum_{i=1}^{n}\left(\hat{y}_{i}-y_{i}\right)\right]^{2}}}{\frac{1}{n} \sum_{i=1}^{n} y_{i}}$.

Note that $y_{i}$ is reference rainfall, $\hat{y}_{i}$ is estimated rainfall for times $i$ from the blended technique, and $n$ is the total number of data points used in the calculations. An NCRMSE value of 0 indicates no random error, while 1 indicates that the random error is equal to $100 \%$ of the mean reference rainfall.

To measure the systematic error, we used the bias ratio (BR) metric, which indicates the mean of the ratio of estimated rainfall to reference rainfall and is defined as

$\mathrm{BR}=\frac{1}{n} \sum_{i=1}^{n}\left(\frac{\hat{y}_{i}}{y_{i}}\right)$.

For an unbiased model, the BR would be 1 .

To assess the ability of the QRF-generated ensemble to encapsulate the reference rainfall, we used the exceedance probability (EP) metric, which indicates the probability that the reference value will exceed the prediction interval:

$\mathrm{EP}=1-\frac{1}{n} \sum_{i=1}^{n} 1_{\left\{Q_{\text {lower }_{i}}<y_{i}<Q_{\text {upper }_{i}}\right\}}$.

Here, $Q_{\text {lower }}$ and $Q_{\text {upper }}$ denote lower and upper boundaries of prediction interval, respectively. The EP would be 0 for an ideal model; that means a perfect encapsulation of the reference within the prediction interval.

To evaluate the accuracy of the QRF-generated ensemble, we used the uncertainty ratio (UR), which measures uncertainty from the prediction interval $\left(Q_{\text {lower }}, Q_{\text {upper }}\right)$, as used in Eq. (3):

$\mathrm{UR}=\frac{\sum_{i=1}^{n}\left(Q_{\text {upper }}-Q_{\text {lower }}\right)}{\sum_{i=1}^{n} y_{i}}$.

To achieve accurate and successful prediction, comparatively small prediction intervals are expected. A UR value of
1 means the best estimate of the actual uncertainty which indicates the maximum possible uncertainty of the prediction interval. The UR quantifies the prediction interval width relative to the magnitude of observations. A UR value close to 1 indicates confidence intervals being in the order of magnitude of the predicted values.

For the evaluation of the accuracy of the ensemble, we also calculated the rank histogram, which is computed by counting the rank of observations and comparing this with values from a compiled ensemble, in ascending order. The rank of the actual value is denoted by $r_{j}\left(r_{1}, r_{2}, \ldots, r_{m+1}\right)$ and $r_{j}$ is expressed as follows:

$r_{j}=\hat{P}\left\{\hat{y}_{i, j-1}<y_{i}<\hat{y}_{i, j}\right\}$.

A flat rank histogram diagram means precise prediction of error distribution (Hamil, 2001; Hamil and Colucci, 1997). A U-shaped rank histogram (convex) represents conditional biases, and a concave shape means an over-spread. Skewing to the right denotes negative bias and vice versa.

The Nash-Sutcliffe efficiency (NSE) is widely used in hydrology to assess model performance (Nash and Sutcliffe, 1970) and is defined as

$\mathrm{NSE}=1-\frac{\sum_{i=1}^{n}\left(\hat{y}_{i}-y_{i}\right)^{2}}{\sum_{i=1}^{n}\left(y_{i}-\bar{y}\right)^{2}}$.

The NSE bounds from negative infinity to positive 1, where positive 1 means ideal consistency. A negative value of NSE denotes the performance of the estimator being worse than the mean of reference.

\section{Results and discussion}

\subsection{Sensitivity analysis}

In this paper we present a blending technique that leads to an improved characterization of precipitation estimation uncertainty through an optimal combination of precipitation and other datasets. The technique is designed to evaluate the sensitivity of the blending technique to the different forcing variables. The selection of variables was based upon recent research works (Seyyedi et al., 2014; Bhuiyan et al., 2017; Mei et al., 2016) that have examined the factors related to precipitation error characteristics and have shown that soil moisture, temperature, precipitation products, and elevation are important predictors in the error modeling of rainfall estimates. Bhuiyan et al. (2017) have recently used a nonparametric statistical technique (QRF) to evaluate the significance of surface soil moisture in modeling the error structure of satellite products and successfully assessed the impact of surface soil moisture information on the model's performance. Therefore, soil moisture is identified as a potential factor for the proposed blending technique instead of the vegetation indicator. In addition, we have daily quality 
controlled surface soil moisture data with a global coverage and $0.25^{\circ}$ spatial resolution while the available vegetation indices are provided at much coarser (multi-day) temporal scales. Also the precipitation products, despite using similar observations to some extent, exhibit different error characteristics and could provide complementary information. Therefore, dynamic (temperature and soil moisture) and static (elevation) land surface variables were used as input along with the multiple global precipitation sources (CMORPH, PERSIANN, and 3B42 (V7); and atmospheric reanalysis precipitation).

After choosing these predictor variables, for any nonparametric statistical technique, it is essential to know the sensitivity of the result to the different input predictor variables and to quantify the impact of change from one variable to another. The variable importance methodology (Breiman, 2001) is a measure of sensitivity in that case, which helps to recognize crucial input variables that demonstrate the relative contribution of each variable. The importance of the predictor variables depends on the magnitude of the percentage increase in mean square error (\% IncMSE) of the model (Breiman, 2001). Higher values of \% IncMSE indicate higher importance of the predictor variables. Briefly, the mean squared error (MSE) computed from the original model (i.e., considering all variables) is compared against MSE from a new model that holds all variables the same as the original model except one, the one of which we want to determine its relative importance.

Results from the variable importance test show that all variables used in this technique contribute valuable information in the modeling process. Results from the variable importance test for two groups included in our methodology (for warm and cold periods, high elevation and rainfall greater than zero for all products) are presented in Fig. 3, which shows the variable importance of the seven predictor variables. According to these results all variables are important but the level of significance varies considerably among the different variables. Soil moisture, reanalysis, and the three satellite precipitation datasets were ranked as the most important predictor variables (Fig. 3), showing their strong impact in model prediction. Similar results (not shown) were obtained from examination of the other scenarios (e.g., for low elevation cases). From the variable importance test, it is argued that all variables selected have a significant impact on the model prediction, justifying our choice for including them.

\subsection{Evaluation of the blending technique}

We first evaluated the method by applying a leave-one-pixelout cross validation, where each pixel was treated as an independent dataset and was predicted based on QRF parameters determined based on the remaining pixels in the database. The time series of 20 ensemble members' cumulative rainfall simulated by QRF for high and low elevations in warm
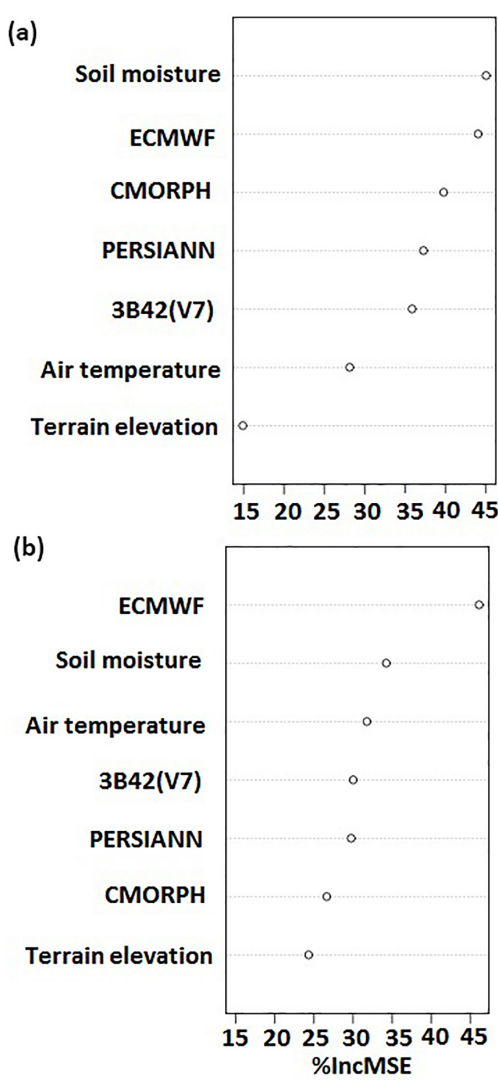

Figure 3. Variable importance plot, where \% IncMSE is the percentage increase in mean square error. (a) Warm period-high elevation. (b) Cold period-high elevation.

and cold seasons are shown in Fig. 4. The ensemble envelope encapsulates the actual rainfall time series, with better convergence of QRF ensemble members for the warm season but with overall satisfying results for the cold season as well. As is shown, the model was capable of generating stochastic realizations that successfully encapsulated the reference precipitation dynamics. Apart from the ensemble performance, one can note from the results in Fig. 4 the variability in the performance of different precipitation products and their inconsistencies relative to the reference precipitation. For example, PERSIANN overestimated high elevation in the warm season, while CMORPH, 3B42 (V7), and atmospheric reanalysis precipitation underestimated it. Overall, CMORPH underestimated the most for both seasons, which indicated poor performance of the QRF ensemble.

Figure 5 compares the combined rainfall product precipitation accumulation maps to the corresponding reference rainfall accumulation maps for the warm and cold seasons. In general, the spatial distribution of rainfall was consistent for both seasons, with the northwestern part of the study area, which is near to the ocean, associated with more precipitation. In the cold season, the combined product gave higher precipitation in the southwestern and northwestern parts of 

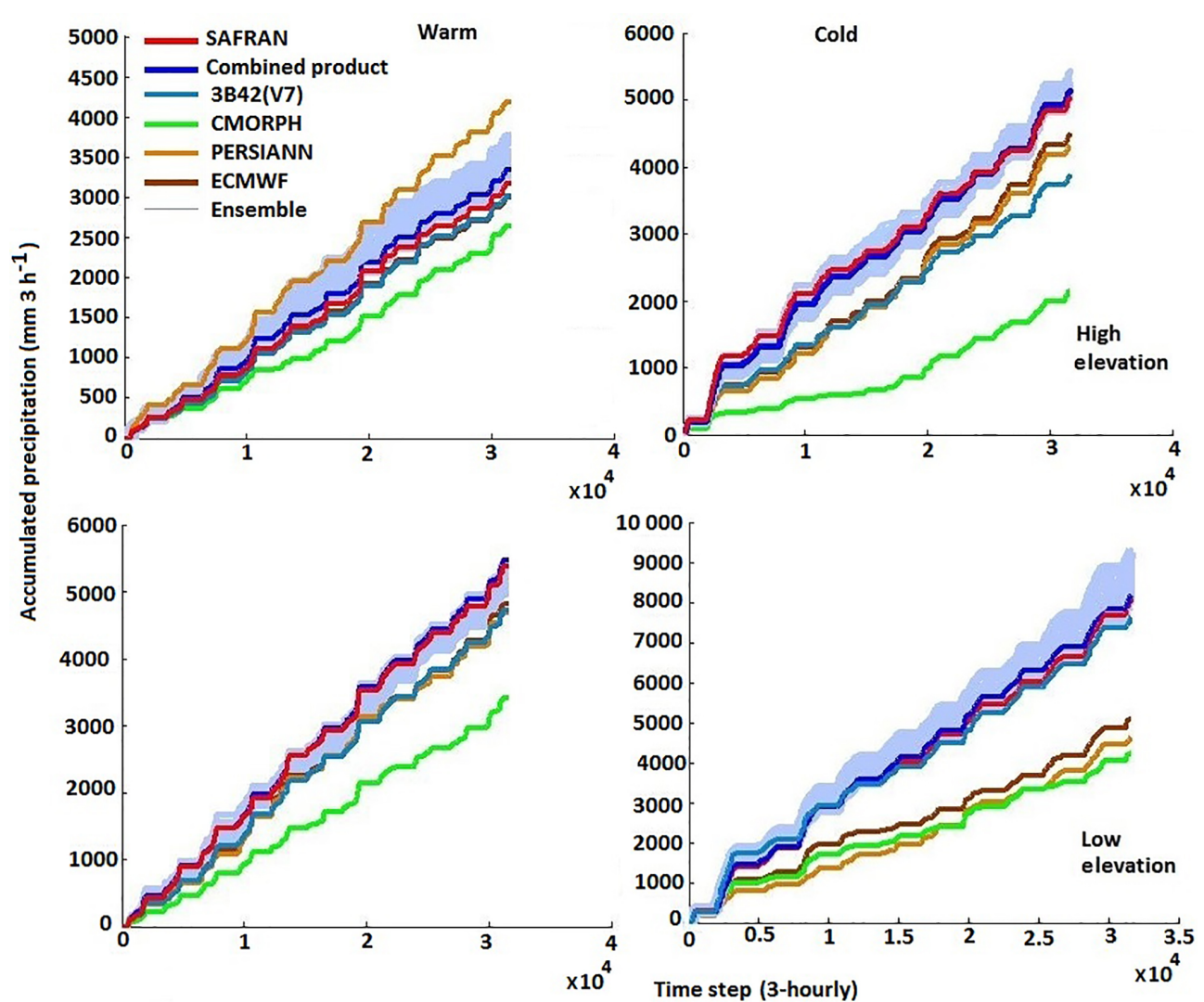

Figure 4. Time series of cumulative rainfall of CMORPH, PERSIANN, 3B42 (V7), reanalysis rainfall, and QRF ensemble (blue envelope) for warm and cold seasons.

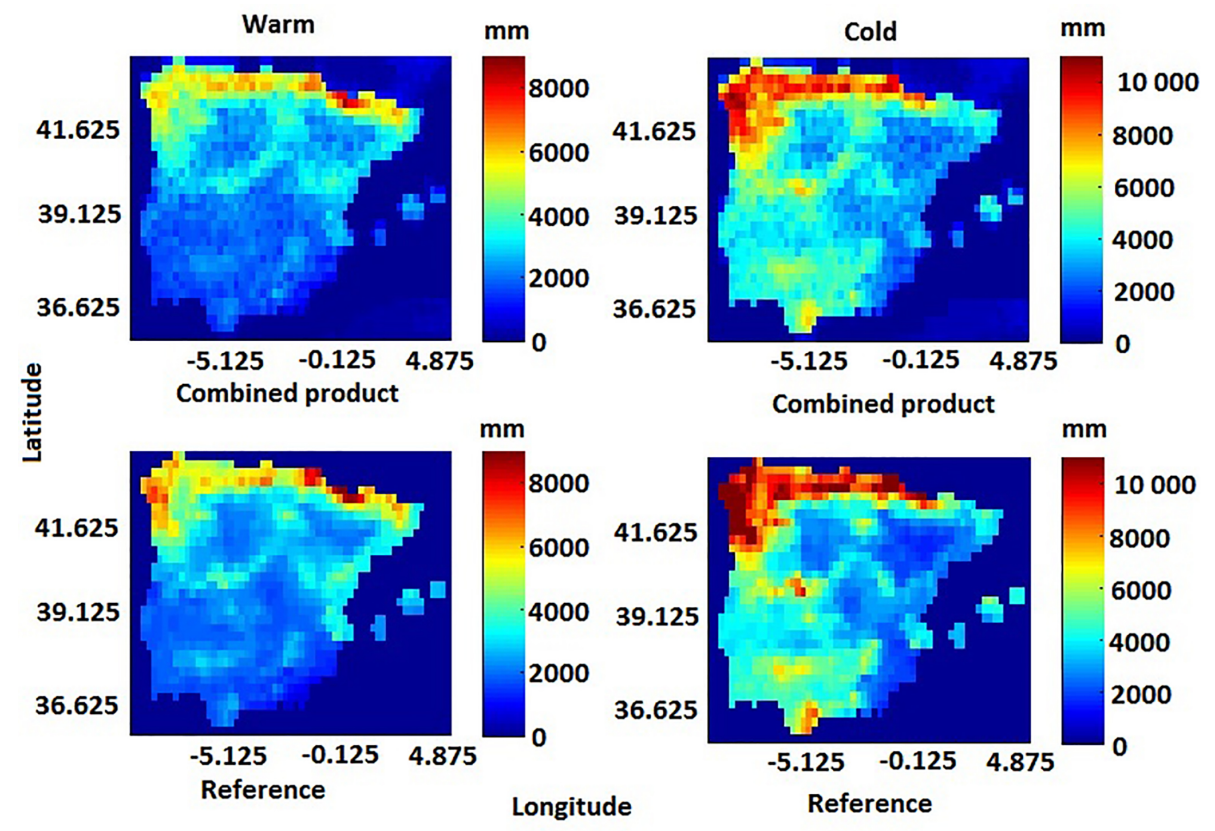

Figure 5. QRF-generated mean ensemble and reference rainfall maps for warm and cold seasons. 


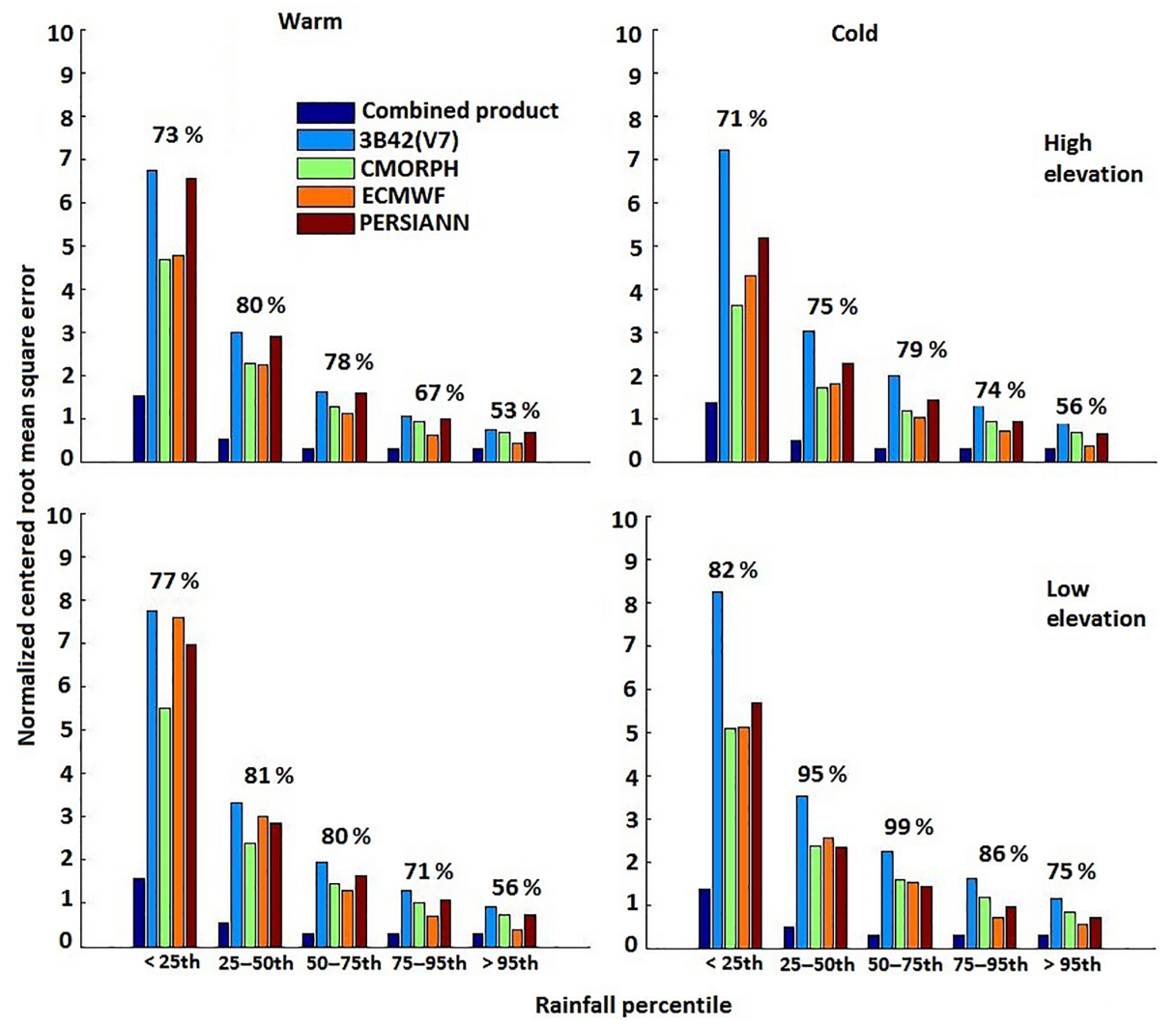

Figure 6. Normalized centered root mean square error for warm and cold seasons. The relative error reductions for the combined product (relative to other products) are shown above the bars.

the Iberian Peninsula than in the warm season. These patterns were consistent with those presented in the reference dataset.

We calculated NCRMSE for the various precipitation products (Fig. 6) for five reference precipitation categories, with values in the percentile ranges of $<25$ th, 25 th-50th, 50th-75th, 75th-95th, and $>95$ th. The results showed the QRF-based combined product could reduce the random error for all rainfall rate categories in both seasons. It is also shown that the random error reduced consistently in all products as the rainfall rate increased.

To quantify the performance of the combined product in contrast to the individual precipitation datasets, we calculated the relative reduction of the NCRMSE for the different precipitation ranges; Fig. 6 presents these performance metric statistics. The relative reduction of the values was defined as the difference between the average of the different datasets and the combined product over the average NCRMSE of the datasets. We noted that relative NCRMSE reduction was greater during the cold season, particularly in regions of low elevation (75 to $99 \%$ ). During the warm season, the relative reduction varied between 53 and $81 \%$ for both high and low elevations. Overall, results from all metrics examined showed that the random error of the combined product was significantly lower than those of the individual global precipitation datasets used in the technique.

The combined product's accuracy was further assessed using BR for both seasons (Fig. 7). The results indicated QRF improved accuracy for rain rates beyond the 50th percentile threshold, exhibiting lower BR values. For moderate to high rainfall in both seasons, all individual rainfall datasets exhibited underestimation, which was reduced in the combined product. For the low rainfall, the systematic error reduction for the combined product was not prominent, resulting in a comparatively higher BR value. Generally, the QRF model is expected not to capture very low and extremely high values well due to the weakness of the empirical distribution function to model probabilities close to 0 or 1 . The sample size plays an important role in empirical distribution function. Therefore, very large sample sizes are required for low values to quantify the rate of convergence to the underlying cumulative distribution function. Moreover, studies have shown that QRF can perform better in generating one-sided prediction intervals, which is the case in Juban et al. (2007), Francke et al. (2008), and Zimmermann et al. (2012). In terms of elevation, the magnitude of BR was considerably less for the high elevations in the warm season. The model used elevation as a control parameter, which reflected its ability to reduce 


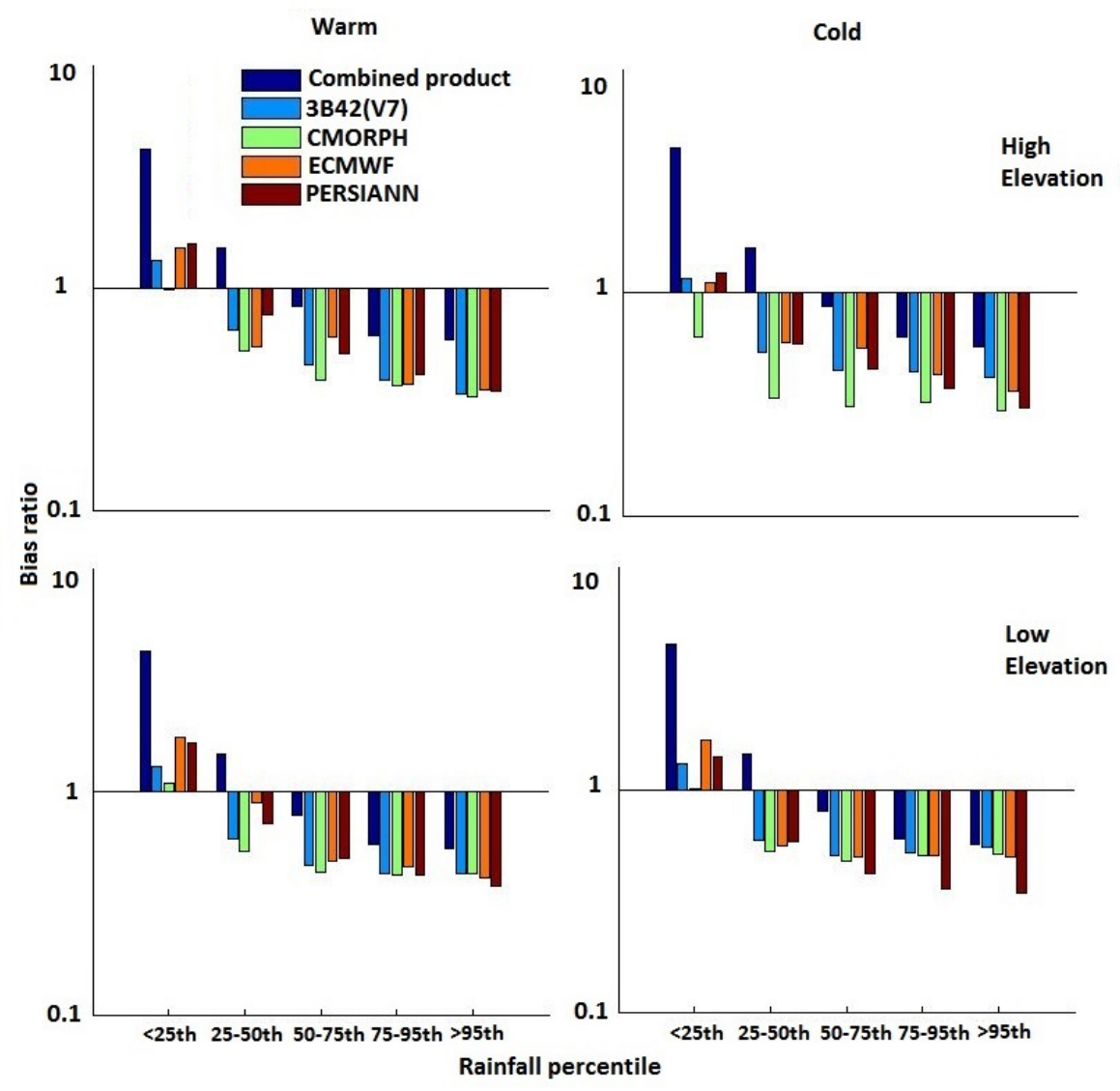

Figure 7. Bias ratio for warm and cold seasons.

the systematic error at high elevations noticeably. For the higher rain rate category ( $>95$ th percentile), the BR value in the warm season ranged between 0.5 and 0.6 , which was close to estimations for the cold season over the study area. The relative reduction was high for the combined product, varying from 17 to $76 \%$ for both seasons. Overall, the combined product exhibited BR values closer to 1 than the individual precipitation datasets did, demonstrating superior performance.

Results for exceedance probability (EP) values (Fig. 8), which are used to assess the ability of the QRF-generated ensemble to encapsulate the reference data, suggest that reference precipitation is captured well within the ensemble envelope. Specifically, considerably reduced exceedance probability values $(<0.26)$ were reported for rain rates below the 95th percentile threshold for both seasons. A season-based comparison revealed that cold-season EP values were smaller than the corresponding values for the warm season across all rain rate thresholds. Even for the high rain rates $(>95$ th percentile), EP values were found to be acceptable $(\sim 0.5)$.

Analysis of UR showed the QRF ensemble envelope was associated with slightly wider prediction intervals in the warm season than in the cold season, indicating varying de- grees of uncertainty throughout the year (Fig. 8). A UR closer to 1 was exhibited for higher rain rates, demonstrating that the ensemble envelope represented the uncertainty for the moderate to high rain rates well, while the variability of the ensemble envelope for rain rates below the 50th percentile threshold overestimated the product uncertainty.

Finally, to evaluate the accuracy of the QRF ensemble, we calculated the rank histogram for the cold and warm seasons. Figure 9 shows the rank histogram of reference values in the posterior sample of QRF ensemble prediction for both seasons. QRF produced a nearly uniformly distributed rank histogram for low to moderate rain rates, which means the rank test was more promising for QRF ensemble predictions for these rain rates. However, the rank histogram exhibited larger values on the right-hand side, indicating underestimation of high rain rates in the ensemble prediction, which is potentially attributed to the inclusion of the entire spectrum of values in the training dataset (i.e., large sample of zeroes and low values) that although allow for reproducing certain important features of precipitation (e.g., intermittency), impact the simulation of high rainfall regime.

As an additional evaluation step, we applied a leave-oneyear-out cross-validation, where we kept a whole year as an 

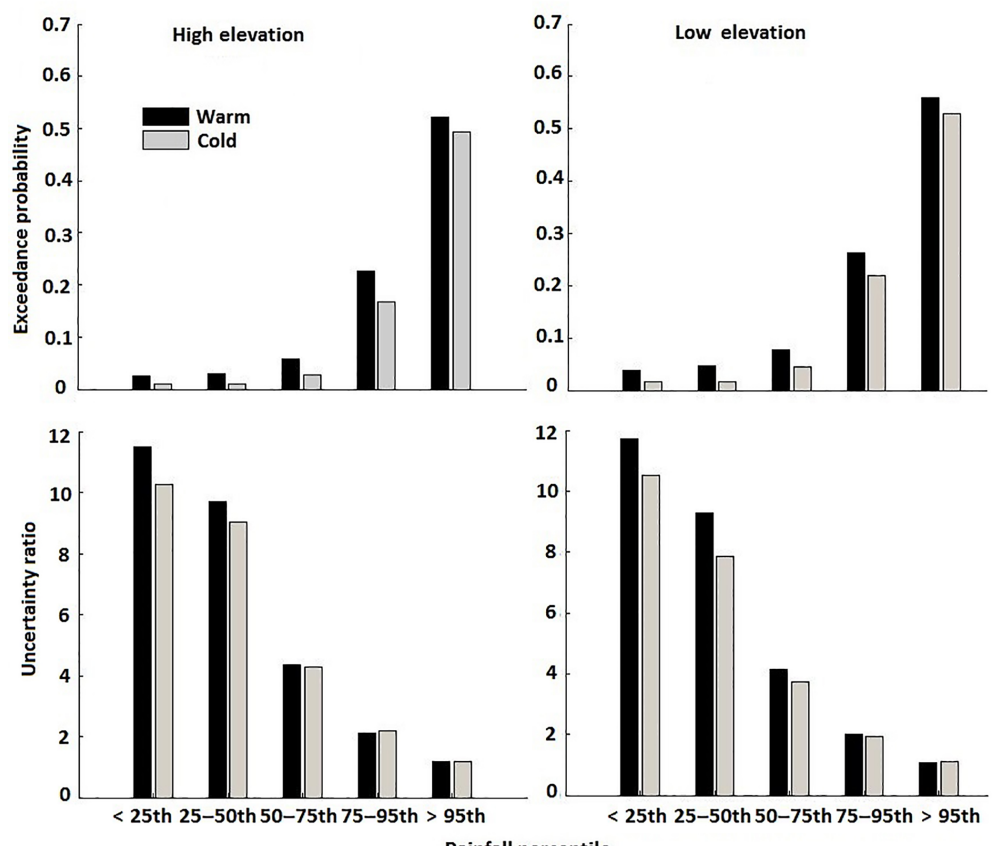

Figure 8. Exceedance probability and uncertainty ratio for warm and cold seasons.

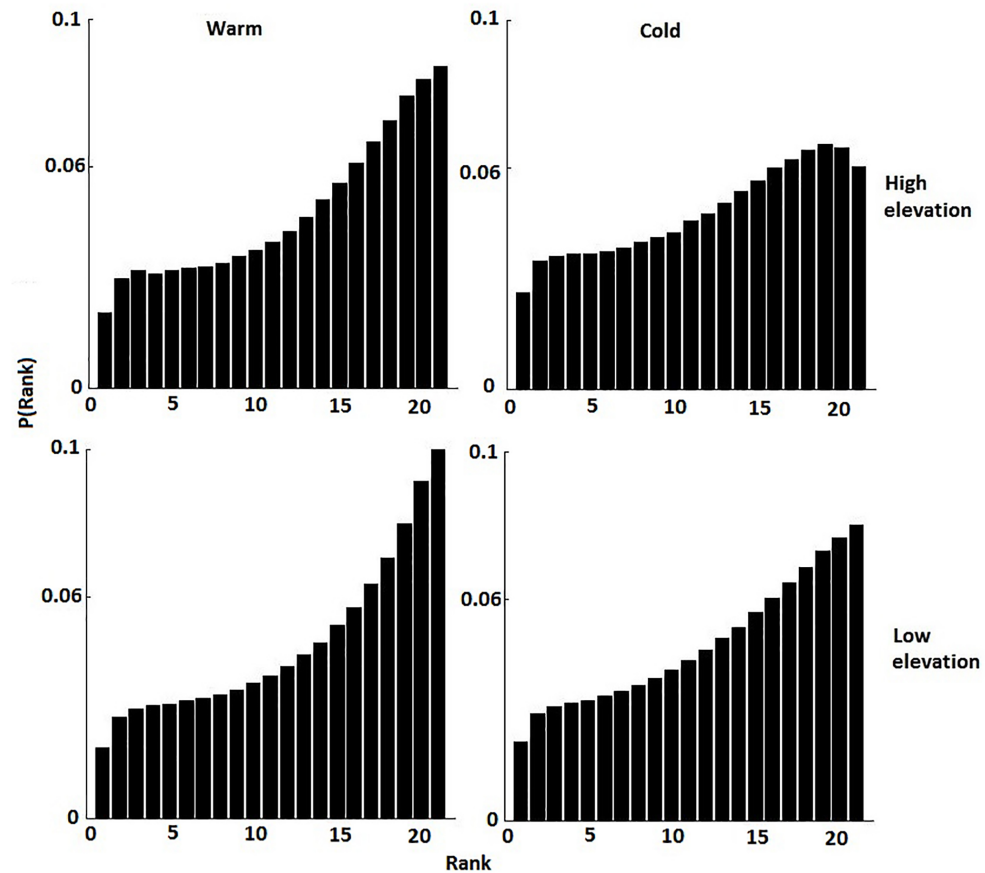

Figure 9. Rank histogram for warm and cold seasons. 


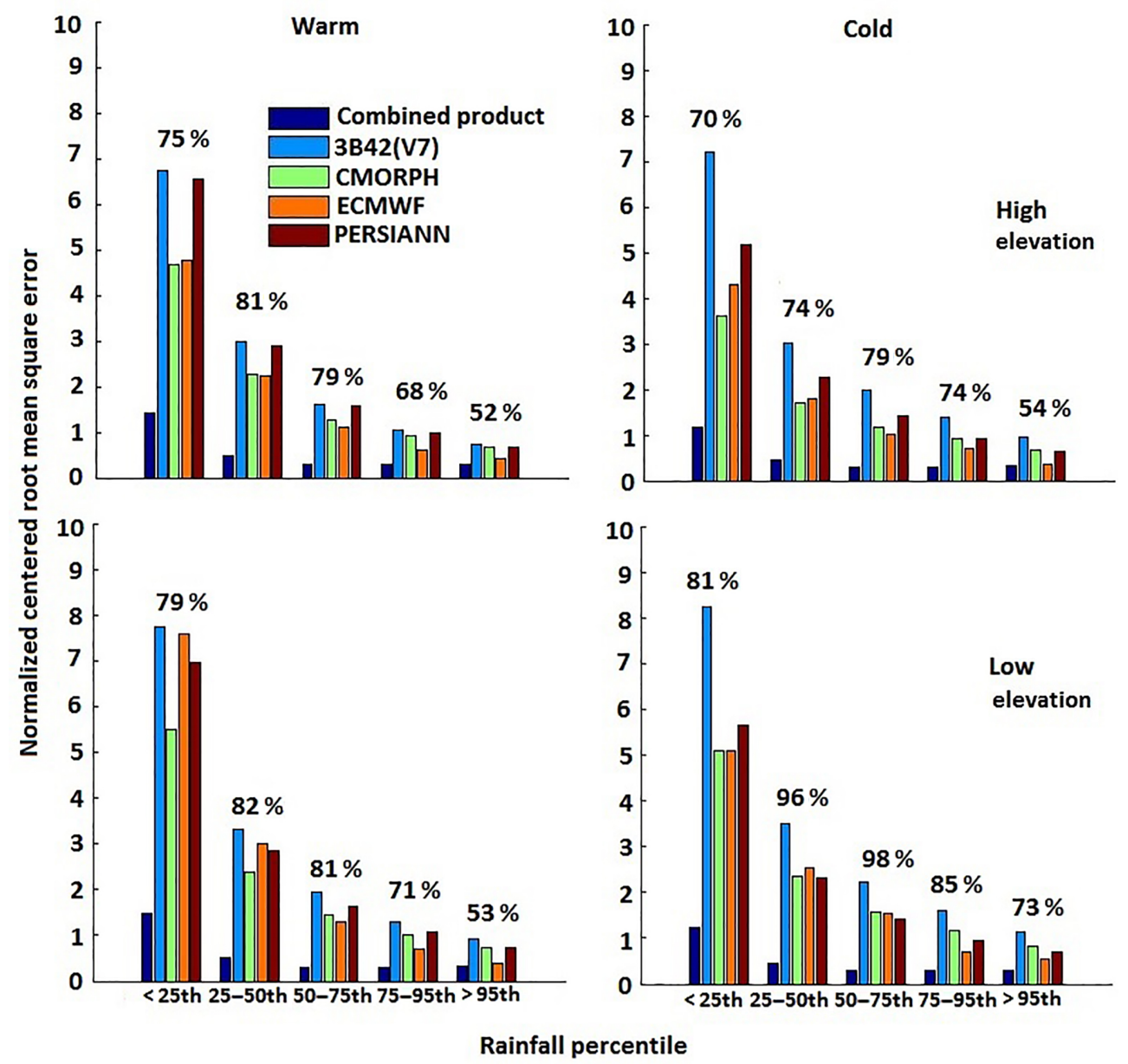

Figure 10. Normalized centered root mean square error for warm and cold season. The relative error reductions for the combined product (relative to other products) are shown above the bars.

independent dataset and the model was trained on the remaining years of the study period. Results for NCRMSE are shown in Fig. 10, which are consistent with the leave-onepixel-out cross-validation analysis in terms of the reduction of the random error for both seasons (warm and cold) and precipitation percentile ranges. The random error decreases with increasing scale, and for all cases, results from the combined product are associated with an error reduction (relative to other products) on the order of 52-98\%. Overall, results indicate that the random error of the combined product was significantly lower than those of the individual precipitation products used in this study.

The performance of the estimates for the model was also evaluated in terms of systematic error, as shown in Fig. 11. Results show that the magnitude of systematic error for the combined product is substantially lower than for the individual precipitation products. Overall, BR values are closer to 1 for moderate to high rain rates in both seasons for the combined product, which indicates that QRF is able to reduce the systematic error in moderate to high rain rates.
In summary, both validation approaches demonstrated that the QRF model is able to reduce the systematic and random error of precipitation estimates exhibited by individual precipitation products significantly, which indicates that QRF was appropriately trained and does not exhibit limitations due to overfitting. To conduct the hydrological simulations in this study, the validation of the results based on the leaveone-pixel-out method is provided in Sect. 4.3.

\subsection{Evaluation of ensemble hydrological simulations}

This section summarizes the results of the streamflow simulations associated with the different precipitation forcing data (satellite, reanalysis, and combined product). We carried out the evaluation using the SAFRAN-based simulations for reference. Comparisons allowed us to understand the performance of each individual precipitation product in terms of streamflow simulations and to evaluate the impact of the QRF-based blending technique in terms of hydrological simulations. The NCRMSE and BR quantitative statistics are 


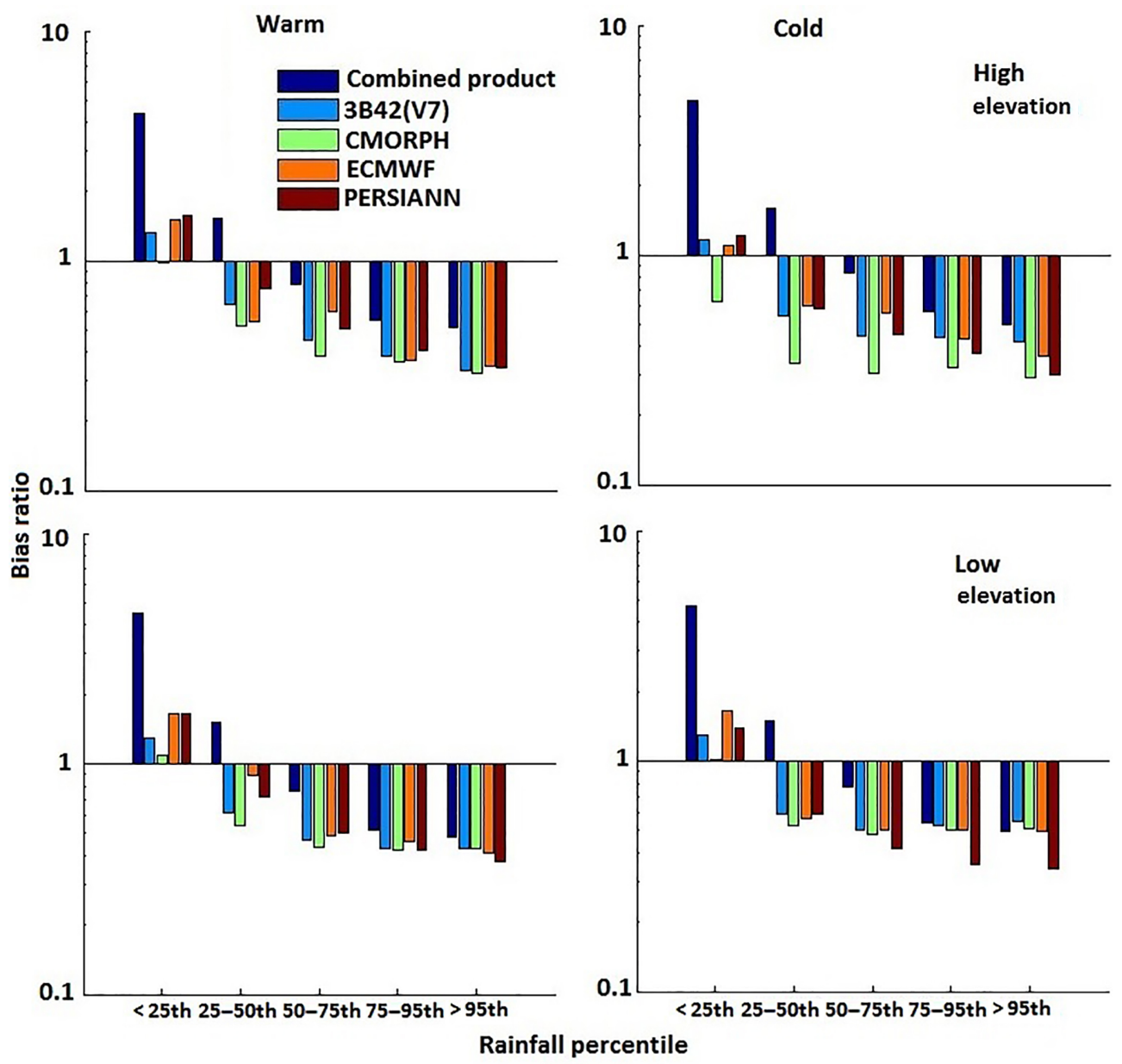

Figure 11. Bias ratio for warm and cold seasons.

used here to assess the performance of basin-scale precipitation forcing data and corresponding generated streamflows.

Since SASER does not simulate dams or canals or irrigation, the simulated streamflow reflects how the flow would be if the water resources of the basin were not managed (that is, naturalized streamflow). The Ebro basin is heavily managed, with hundreds of dams and an important canal network. This raised the problem that model flows could not be compared to the observed flows on those subbasins that are influenced by water management, which is most of them. The Spanish Ministry of Agriculture, Fisheries, Food, and the Environment (MAPAMA) had, however, produced monthly naturalized river flows using the SIMPA rain-runoff model (Ruiz et al., 1998; Álvarez et al., 2004). These are the reference values used by the managers, and they currently offer the only means of reference for validating SASER results.

Table 1 compares the bias and NSE of SASER to those of SIMPA. In terms of monthly accumulation of precipitation, the precipitation data used by SIMPA were similar to SAFRAN's; thus, the difference may have resided in evapotranspiration, which is calculated differently in both mod- els, in terms of both formulation and land-use maps. In terms of NSE, the scores are acceptable at the outlet (between 0.4 and 0.6) and better at most Pyrenean basins (between 0.4 and 0.8 ), with some exceptions.

Although SASER had room for improvement, mainly with regard to bias, the model was generally able to simulate the main dynamics of the basin. In fact, given that it is essentially evaluated against another model (SIMPA) the reported bias cannot be attributed with certainty to a deficiency of the SASER model, and therefore this evaluation exercise mostly shows that the model we used can represent flows consistently (to a certain degree) with another model that is widely used in the region. As this study aimed to evaluate streamflow simulations in a relative sense (that is, with respect to SAFRAN-based simulations) and not to reproduce the observed river flows with precision, the current version of the SASER model was considered adequate for this purpose. Being physically based, it simulated the interplay among different physical processes realistically, and, thus, it could be used to assess their impact on uncertainty. 
Table 1. The bias and NSE of high-resolution SAFRAN-SURFEX simulation.

\begin{tabular}{|c|c|c|c|c|}
\hline River & Station & $\begin{array}{r}\text { Area NSE } \\
\left(\mathrm{km}^{2}\right)\end{array}$ & Bias & \\
\hline Ega & Andosilla & 1445 & 0.735 & -13.52 \\
\hline Arga & Funes & 2759 & 0.651 & -38.068 \\
\hline Aragón & Caparroso & 5462 & 0.733 & -25.655 \\
\hline Jiloca & Daroca & 2202 & 0.069 & -23.28 \\
\hline Ebro & Zaragoza & 40434 & 0.716 & -29.324 \\
\hline Gállego & Ardisa & 2040 & 0.477 & -26.613 \\
\hline Ésera & Graus & 893 & 0.37 & -28.177 \\
\hline Cinca & El Grado & 2127 & 0.629 & -21.223 \\
\hline Segre & Lleida & 11369 & 0.256 & -35.016 \\
\hline Ebro & Tortosa & 84230 & 0.576 & -27.2 \\
\hline Najerilla & Mansilla & 242 & 0.114 & -62.214 \\
\hline Albercos & Ortigosa & 45 & 0.193 & -45.826 \\
\hline Cidacos & Yanguas & 223 & 0.392 & -42.551 \\
\hline Salazar & Aspurz & 396 & 0.731 & -27.012 \\
\hline Irati & Liedena & 1546 & 0.721 & -30.451 \\
\hline Arga & Echauri & 1756 & 0.508 & -46.398 \\
\hline Ega & Estella & 943 & 0.622 & -36.172 \\
\hline Aragón & Yesa & 2191 & 0.716 & -22.334 \\
\hline Noguera & Collegats & 1518 & -0.768 & 2.102 \\
\hline \multicolumn{5}{|l|}{ Pallaresa } \\
\hline Huerva & Mezcalocha & 620 & 0.427 & -24.375 \\
\hline Ebro & Mendavia & 12010 & 0.592 & -36.507 \\
\hline Ebro & Flix & 82416 & 0.59 & -27.564 \\
\hline Ésera & Barasona & 1511 & 0.446 & -32.846 \\
\hline Ebro & Ribarroja & 81060 & 0.595 & -27.604 \\
\hline Jalón & Calatayud & 6841 & 0.222 & -22.072 \\
\hline
\end{tabular}

To provide an overview of the differences in error magnitude between forcing and response variables, we present our analysis of error metrics for simulated streamflow along with corresponding error metrics in basin-average precipitation. Results for NCRMSE are shown in Fig. 12, which notes that for the two larger basins, Ebro at Tortosa $\left(84230 \mathrm{~km}^{2}\right)$ and Ebro at Zaragoza ( $\left.40434 \mathrm{~km}^{2}\right)$, the NCRMSE (0.1-0.3) of the combined product was significantly lower than those of the other subbasins for all intervals of streamflow values; this was related to the significant smoothing effect on random error associated with larger basin scales.

Consistent with streamflow, these two basins also exhibited considerably lower NCRMSE values $(0.2-0.5)$ for the combined product in terms of basin-average precipitation. The random component of error was generally slightly higher for low precipitation rates than for the moderate and higher rates for the five subbasins. Similar findings in NCRMSE values for the low streamflow rates were observed. For the basin-average precipitation, the relative NCRMSE reduction was high for the combined product, ranging from 84 to $88 \%$ (below the 25 th percentile group). A product-wise comparison showed the combined product had more significant error-dampening effects than reanalysis and satel- lite precipitation products in streamflow simulation for all the subbasins. Specifically, the combined product (above the 50th percentile) was characterized by a noticeably relative error reduction (44 to $78 \%$ ) for streamflow. Moreover, we also observed that relative error reduction for the combined product decreased remarkably (56 to $88 \%$ ) for low streamflow. These results indicated random error was reduced through the rainfall-streamflow transformation in all subbasins. Overall, results show combining information from reanalysis and satellite precipitation datasets could decrease random error in streamflow simulations.

The bias ratio (BR) for basin-average precipitation ranges from overestimation to underestimation as a function of precipitation magnitude, with precipitation rates above the 50th percentile strongly underestimated (BR in the range of 0.07-0.25) (Fig. 13). The magnitude of BR for precipitation indicated lower systematic errors in estimates of low to high basin-average precipitation for all subbasins. The corresponding BR values for the simulated streamflows provided a general appreciation of how the magnitude of systematic error in basin-average precipitation translates to systematic error in streamflow simulations. While a one-to-one correspondence between rainfall and streamflow classes was not possible (note that an event from the highest rainfall class might have resulted in moderate flow values depending on antecedent conditions and so on), we could, however, compare the overall range of $\mathrm{BR}$ values between basin-average precipitation and streamflow. As Fig. 13 indicates for the combined product, BR values were closer to 1 for the different streamflow classes, indicating that streamflow was relatively stable. For the two larger basins, Ebro at Tortosa and Ebro at Zaragoza, the combined product underestimated actual values slightly. Overall, the relative systematic error reduction for streamflow ranged from 20 to $99 \%$. These results highlight the usefulness of optimally combining satellite and reanalysis precipitation datasets. Overall, after reducing systematic error, the QRF-generated ensemble corrections brought rainfall products closer to the reference rainfall and simulated runoff.

\section{Conclusions}

A new framework was presented in this study that uses a nonparametric technique (QRF) to combine multiple globally available data sources, including reanalysis and gaugeadjusted satellite precipitation datasets, for generating an improved ensemble precipitation product. The study investigated the accuracy of the combined product using a highresolution reference rainfall dataset (SAFRAN) over the Iberian Peninsula. The QRF-generated ensemble members are evaluated in terms of precipitation for both warm- and cold-season weather patterns, representing a wide variety of precipitation events. Furthermore, the QRF-based streamflow simulations from a distributed hydrological model are 


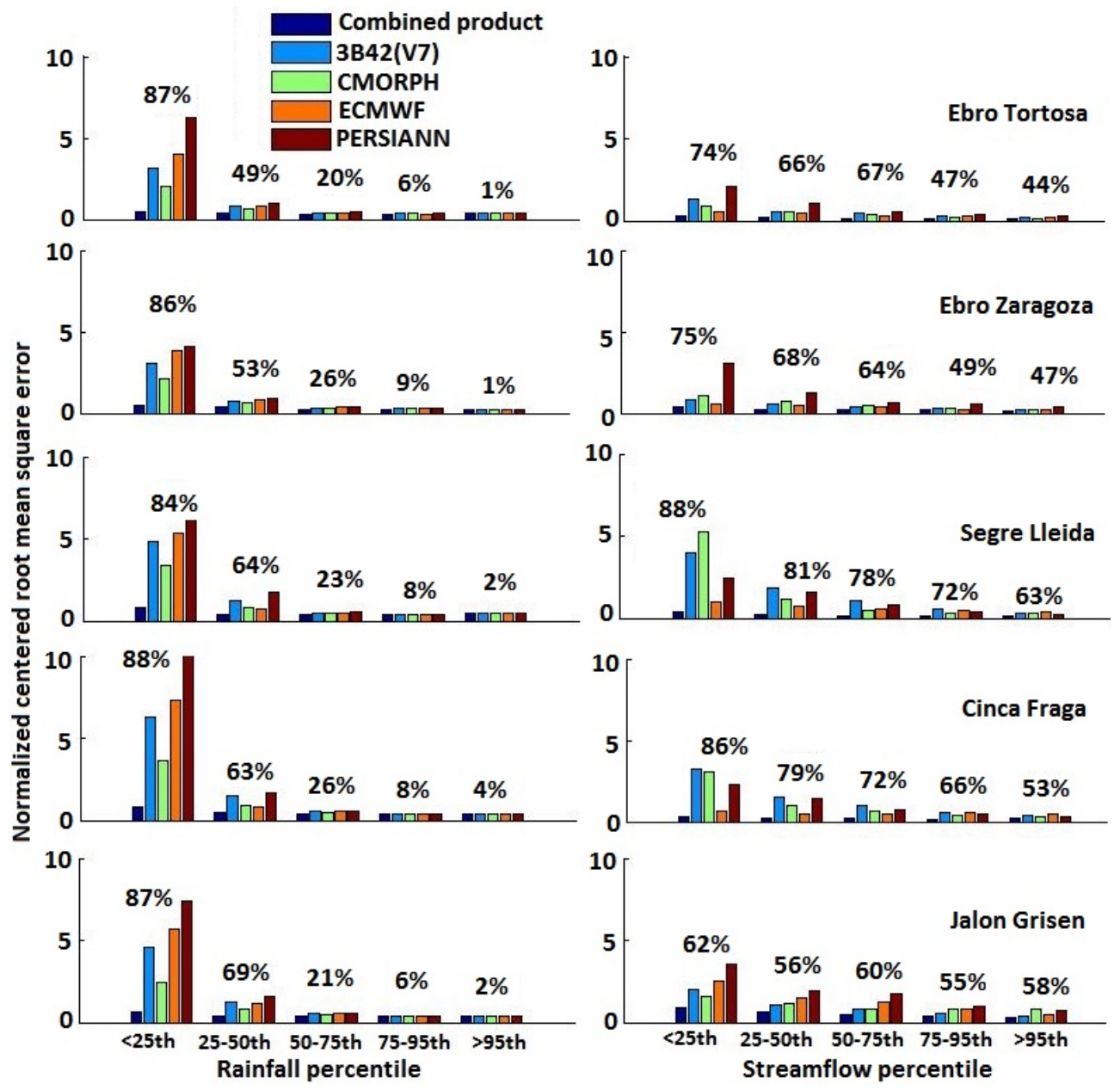

Figure 12. Normalized centered root mean square error for basin-average rainfall and streamflow. The relative error reductions for the combined product (relative to other products) are shown above the bars.

evaluated against the SAFRAN-based simulations for a range of basin scales of the Ebro River basin.

Results from the analysis carried out demonstrate clearly that the proposed blending technique has the potential to generate a realistic precipitation ensemble that is statistically consistent with the reference precipitation and is associated with considerably reduced errors. In terms of seasonality effects, the random error significantly decreased for the combined product with increasing rainfall magnitude, and this reduction was greater during the cold season. The systematic error of the combined product varied from over- to underestimation as rain rate increased during both seasons. In terms of elevation, among all individual products, the magnitude of systematic error for the combined product was noticeably decreased for the higher elevations, which is a strong indication for using the proposed scheme in retrieving global precipitation in high-elevation regions. Overall, the reduction of the combined product (relative to other products) for the system- atic and random error ranged between 17 and 76 and 53 and $99 \%$, respectively.

Evaluation of the impact on streamflow simulations showed that the magnitude of systematic and random error for simulations corresponding to the combined product was significantly lower than for the individual precipitation products. In addition, for the combined product, the large-scale basins exhibited considerably lower systematic and random error values than the small-size basins, which shows the dependency on basin scale. Specifically, the relative reduction for the combined product in systematic and random error ranged between 20 and 99 and 44 and $88 \%$, respectively, which highlights the potential of the proposed technique in advancing hydrologic simulations.

Our overall conclusion is that the proposed framework offers a robust way of blending globally available precipitation datasets, providing at the same time an improved precipitation product and characterization of its uncertainty. This can 

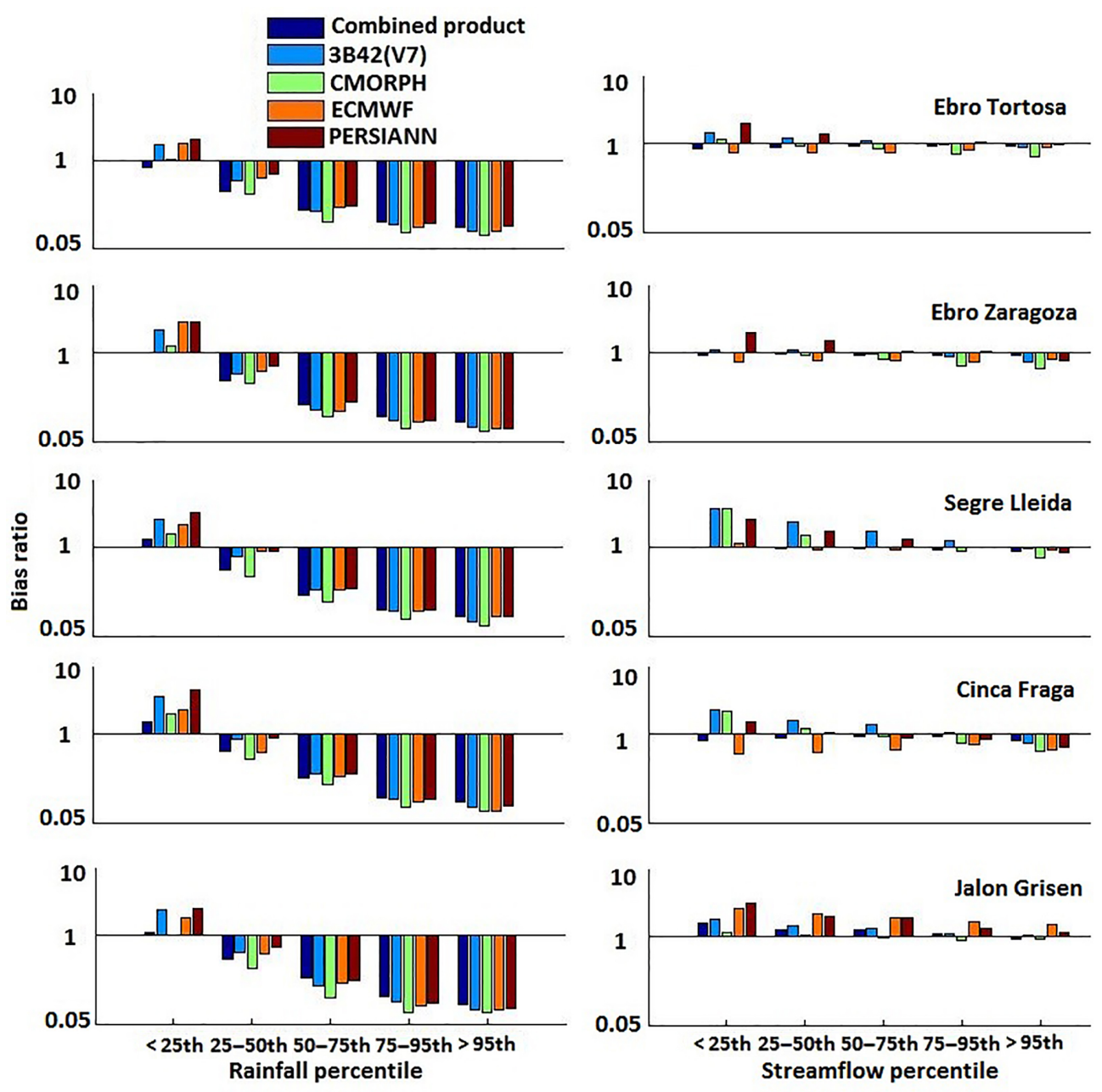

Figure 13. Bias ratio of precipitation and streamflow.

have important applications in studies dealing with water resources reanalysis and quantification of uncertainty in hydrologic simulations. Future work will include evaluation of the proposed framework in different hydroclimatic regions, also considering the sensitivity of its performance to availability (e.g., record length and spatial coverage) of in situ reference precipitation.

Data availability. Several datasets were used for this paper. The SAFRAN dataset for Spain was obtained from the MISTRALS HyMeX database (https://doi.org/10.14768/ MISTRALS-HYMEX.1388). The other datasets are also available online: CMORPH (ftp://ftp.cpc.ncep.noaa.gov/ precip/CMORPH_V1.0/RAW/0.25deg-3HLY/), PERSIANN (http://fire.eng.uci.edu/PERSIANN/data/3hrly_adj_cact_tars/),

3B42 (V7) (https://mirador.gsfc.nasa.gov), atmospheric reanalysis dataset (https://wci.earth2observe.eu/portal/), satellite-derived near-surface daily soil moisture data (http://www.esa-soilmoisture-cci.org/node/145/), terrain elevation data (http://srtm.csi.cgiar.org/SELECTION/inputCoord.asp), and the combined product (https://sites.google.com/uconn.edu/ ehsanbhuiyan/research).

Competing interests. The authors declare that they have no conflict of interest.

Acknowledgements. This research was supported by the FP7 project eartH2Observe (grant agreement no. 603608).

Edited by: Hannah Cloke

Reviewed by: Viviana Maggioni and Seyed Hamed Alemohammad 


\section{References}

Adler, R. F., Kidd, C., Petty, G., Morissey, M., and Goodman, H. M.: Intercomparison of global precipitation products: the third precipitation intercomparison project (PIP-3), B. Am. Meteorol. Soc., 82, 1377-1396, 2001.

AghaKouchak, A., Nasrollahi, N., and Habib, E.: Accounting for uncertainties of the TRMM Satellite Estimates, Remote Sens., 1, 606-619, 2009.

Álvarez, J., Sánchez, A., and Quintas, L.: SIMPA, a GRASS based tool for hydrological studies, in: Proceedings of the FOSS/GRASS Users Conference, Bangkok, Thailand, 2004.

Bhuiyan, M. A. E., Anagnostou, E. N, and Kirstetter, P. E.: A nonparametric statistical technique for modeling overland TMI (2A12) rainfall retrieval error, IEEE Geosci. Remote S., 14, 1898-1902, 2017.

Bitew, M. M. and Gebremichael, M.: Evaluation of satellite rainfall products through hydrologic simulation in a fully distributed hydrologic model, Water Resour. Res., 47, W06526, https://doi.org/10.1029/2010WR009917, 2011.

Boone, A.: Modélisation des processus hydrologiques dans le schéma de surface ISBA: Inclusion d'un réservoir hydrologique, du gel et modélisation de la neige, Université Paul Sabatier (Toulouse III), Toulouse, available at: http://www.cnrm.meteo.fr/ IMG/pdf/boone_thesis_2000.pdf, 2000.

Breiman, L.: Random forests, Mach. Learn., 45, 5-32, 2001.

Brown, J. D. and Seo, D. J.: A nonparametric postprocessor for bias correction of hydrometeorological and hydrologic ensemble forecasts, J. Hydrometeorol., 11, 642-665, 2010.

Champeaux, J. L., Masson, V., and Chauvin, F.: ECOCLIMAP: a global database of land surface parameters at $1 \mathrm{~km}$ resolution, Meteorol. Appl., 12, 29-32, 2005.

Chipman, H. A., George, E. I., and McCulloch, R. E.: Bart: Bayesian additive regression trees, Ann. Appl. Stat., 4, 266-298, 2010.

Ciach, G. J., Krajewski, W. F., and Villarini, G.: Product-errordriven uncertainty model for probabilistic quantitative precipitation estimation with NEXRAD data, J. Hydrometeorol., 8, 13251347, https://doi.org/10.1175/2007JHM814.1, 2007.

Croley, T. E.: Weighted-climate parametric hydrologic forecasting, J. Hydrol. Eng., 8, 8171-8180, 2003.

David, C. H., Maidment, D. R., Niu, G. Y., Yang, Z. L., Habets, F., and Eijkhout, V.: River network routing on the NHDPlus dataset, J. Hydrometeorol., 12, 913-934, 2011a.

David, C. H., Habets, F., Maidment, D. R., and Yang, Z. L.: RAPID applied to the SIM-France model, Hydrol. Process., 25, 3412 3425, $2011 \mathrm{~b}$.

De Jeu, R. A.: Retrieval of land surface parameters using passive microwave remote sensing, PhD Dissertation, VU Amsterdam, the Netherlands, 120 pp., 2003.

Decharme, B., Boone, A., Delire, C., and Noilhan, J.: Local evaluation of the interaction between soil biosphere atmosphere soil multilayer diffusion scheme using four pedotransfer functions, J. Geophys. Res.-Atmos., 116, https://doi.org/10.1029/2011JD016002, 2011.

Dee, D. P., Uppala, S. M., Simmons, A. J., Berrisford, P., Poli, P., Kobayashi, S., Andrae, U., Balmaseda, M. A., Balsamo, G., Bauer, P., and Bechtold, P.: The ERA-Interim reanalysis: configuration and performance of the data assimilation system, Q. J. Roy. Meteor. Soc., 137, 553-597, 2011.
Derin, Y., Anagnostou, E., Berne, A., Borga, M., Boudevillain, B., Buytaert, W., Chang, C. H., Delrieu, G., Hong, Y., Hsu, Y. C., and Lavado-Casimiro, W.: Multiregional satellite precipitation products evaluation over complex terrain, J. Hydrometeorol., 17, 1817-1836, https://doi.org/10.1175/JHM-D-15-0197.1, 2016.

Durand, Y., Brun, E., Merindol, L., Guyomarc'h, G., Lesaffre, B., and Martin, E.: A meteorological estimation of relevant parameters for snow models, Ann. Glaciol., 18, 65-71, 1993.

Francke, T., López-Tarazón, J. A., Vericat, D., Bronstert, A., and Batalla, R. J.: Flood-based analysis of high-magnitude sediment transport using a non-parametric method, Earth Surf. Proc. Land., 33, 2064-2077, 2008.

Gebremichael, M., Liao, G. Y., and Yan, J.: Nonparametric error model for a high resolution satellite rainfall product, Water Resour. Res., 47, W07504, https://doi.org/10.1029/2010WR009667, 2011.

Gottschalck, J., Meng, J., Rodell, M., and Houser, P.: Analysis of multiple precipitation products and preliminary assessment of their impact on global land data assimilation system land surface states, J. Hydrometeorol., 6, 573-598, https://doi.org/10.1175/JHM437.1, 2005.

Guikema, S. D., Quiring, S. M., and Han, S. R.: Prestorm estimation of hurricane damage to electric power distribution systems, Risk Anal., 30, 1744-1752, 2010.

Hamill, T. M.: Interpretation of rank histograms for verifying ensemble forecasts, Mon. Weather Rev., 129, 550-560, 2001.

Hamill, T. M. and Colucci, S. J.: Verification of Eta-RSM shortrange ensemble forecasts, Mon. Weather Rev., 125, 1312-1327, 1997.

Harding, R., Best, M., Blyth, E., Hagemann, S., Kabat, P., Tallaksen, L. M., Warnaars, T., Wiberg, D., Weedon, G. P., Lanen, H. V., and Ludwig, F.: WATCH: current knowledge of the terrestrial global water cycle, J. Hydrometeorol., 12, 1149-1156, 2011.

He, J., Wanik, D., Hartman, B., Anagnostou, E., Astitha, M., and Frediani, M. E. B.: Nonparametric tree-based predictive modeling of storm damage to power distribution network, Risk Anal., 37, 441-458, https://doi.org/10.1111/risa.12652, 2017.

Hossain, F. and Anagnostou, E. N.: Assessment of current passivemicrowave- and infrared-based satellite rainfall remote sensing for flood prediction, J. Geophys. Res., 109, D07102, https://doi.org/10.1029/2003JD003986, 2004.

Hossain, F. and Anagnostou, E. N.: Assessment of a multidimensional satellite rainfall error model for ensemble generation of satellite rainfall data, IEEE Trans. Geosci. Remote Sens. Lett., 3, 419-423, 2006.

Hou, A. Y., Kakar, R. K., Neeck, S., Azarbarzin, A. A., Kummerow, C. D., Kojima, M., Oki, R., Nakamura, K., and Iguchi, T. The global precipitation measurement mission, B. Am. Meteorol. Soc., 95, 701-722, https://doi.org/10.1175/BAMS-D-1300164.1, 2014.

Huffman, G. J., Bolvin, D. T., Nelkin, E. J., Wolff, D. B., Adler, R. F., Gu, G., Hong, Y., Bowman, K. P., and Stocker, E. F.: The TRMM Multisatellite Precipitation Analysis (TMPA): quasi-global, multiyear, combined-sensor precipitation estimates at fine scales, J. Hydrometeorol., 8, 38-55, https://doi.org/10.1175/JHM560.1, 2007.

Huffman, G. J., Adler, R. F., Bolvin, D. T., and Nelkin, E. J.: The TRMM multi-satellite precipitation analysis (TMPA), in: Satel- 
lite rainfall applications for surface hydrology, edited by: Gebremichael, M. and Hossain, F., Springer, Dordrecht, 3-22, 2010.

Joyce, R. J., Janowiak, J. E., Arkin, P. A., and Xie, P.: CMORPH: a method that produces global precipitation estimates from passive microwave and infrared data at high spatial and temporal resolution, J. Hydrometeorol., 5, 487-503, 2004.

Juban, J., Fugon, L., and Kariniotakis, G.: Probabilistic short-term wind power forecasting based on kernel density estimators, in: European Wind Energy Conference and exhibition, EWEC 2007, 7-10 May 2017, Milan, Italy, 2007.

Lakhankar, T., Ghedira, H., Temimi, M., Sengupta, M., Khanbilvardi, R., and Blake, R.: Non-parametric methods for soil moisture retrieval from satellite remote sensing data, Remote Sens.Basel, 1, 3-21, https://doi.org/10.3390/rs1010003, 2009.

Lehner, B., Verdin, K., and Jarvis, A.: New global hydrography derived from spaceborne elevation data, Eos, 89, 93-94, 2008.

Li, L., Hong, Y., Wang, J., Adler, R. F., Policelli, F. S., Habib, S., Irwn, D., Korme, T., and Okello, L.: Evaluation of the real-time TRMM-based multi-satellite precipitation analysis for an operational flood prediction system in Nzoia basin, Lake Victoria, Africa, Nat. Hazards, 50, 109-123, https://doi.org/10.1007/s11069-008-9324-5, 2009.

Liu, Y. Y., Parinussa, R. M., Dorigo, W. A., De Jeu, R. A. M., Wagner, W., van Dijk, A. I. J. M., McCabe, M. F., and Evans, J. P.: Developing an improved soil moisture dataset by blending passive and active microwave satellite-based retrievals, Hydrol. Earth Syst. Sci., 15, 425-436, https://doi.org/10.5194/hess-15425-2011, 2011.

Liu, Y. Y., Dorigo, W. A., Parinussa, R. M., de Jeu, R. A., Wagner, W., McCabe, M. F., Evans, J. P., and Van Dijk, A. I. J. M.: Trend-preserving blending of passive and active microwave soil moisture retrievals, Remote Sens. Environ., 123, 280-297, 2012.

Maggioni, V., Sapiano, M. R., Adler, R. F., Tian, Y., and Huffman, G. J.: An error model for uncertainty quantification in hightime-resolution precipitation products, J. Hydrometeorol., 15, 1274-1292, https://doi.org/10.1175/JHM-D-13-0112.1, 2014.

Maggioni, V., Massari, C., Brocca, L., and Ciabatta, L.: Merging bottom-up and top-down precipitation products using a stochastic error model, J. Geophys. Res., 19, 12383, 2017.

Masson, V., Le Moigne, P., Martin, E., Faroux, S., Alias, A., Alkama, R., Belamari, S., Barbu, A., Boone, A., Bouyssel, F., Brousseau, P., Brun, E., Calvet, J.-C., Carrer, D., Decharme, B., Delire, C., Donier, S., Essaouini, K., Gibelin, A.-L., Giordani, H., Habets, F., Jidane, M., Kerdraon, G., Kourzeneva, E., Lafaysse, M., Lafont, S., Lebeaupin Brossier, C., Lemonsu, A., Mahfouf, J.-F., Marguinaud, P., Mokhtari, M., Morin, S., Pigeon, G., Salgado, R., Seity, Y., Taillefer, F., Tanguy, G., Tulet, P., Vincendon, B., Vionnet, V., and Voldoire, A.: The SURFEXv7.2 land and ocean surface platform for coupled or offline simulation of earth surface variables and fluxes, Geosci. Model Dev., 6, 929-960, https://doi.org/10.5194/gmd-6-929-2013, 2013.

Mei, Y., Anagnostou, E. N., Nikolopoulos, E. I., and Borga, M.: Error analysis of satellite rainfall products in mountainous basins, J. Hydrometeorol., 15, 1778-1793, https://doi.org/10.1175/JHM-D-13-0194.1, 2014.

Mei, Y., Nikolopoulos, E. I., Anagnostou, E. N., and Borga, M.: Evaluating satellite precipitation error propagation in runoff simulations of mountainous basins, J. Hydrometeorol., 17, 14071423, https://doi.org/10.1175/JHM-D-15-0081.1, 2016.
Meinshausen, N.: Quantile regression forests, J. Mach. Learn. Res., 7, 983-999, 2006.

Mo, K. C., Chen, L. C., Shukla, S., Bohn, T. J., and Lettenmaier, D. P.: Uncertainties in North American land data assimilation systems over the contiguous United States, J. Hydrometeorol., 13, 996-1009, https://doi.org/10.1175/JHM-D-11-0132.1, 2012.

Mujumdar, P. P. and Ghosh, S.: Climate change impact on hydrology and water resources, J. Hydraul. Eng., 14, 1-17, 2008.

Nash, J. E. and Sutcliffe, J. V.: River flow forecasting through conceptual models part I - a discussion of principles, J. Hydrol., 10, 282-290, 1970.

Nateghi, R., Guikema, S. D., and Quiring, S. M.: Forecasting hurricane-induced power outage durations, Nat. Hazards, 74, 1795-1811, 2014

Nikolopoulos, E. I., Anagnostou, E. N., and Borga, M.: Using highresolution satellite rainfall products to simulate a major flash flood event in Northern Italy, J. Hydrometeorol., 14, 171-185, https://doi.org/10.1175/JHM-D-12-09.1, 2013.

Noilhan, J. and Mahfouf, J. F.: The ISBA land surface parameterisation scheme, Global Planet. Change, 13, 145-159, 1996.

Noilhan, J. and Planton, S.: A simple parameterization of land surface processes for meteorological models, Mon. Weather Rev., 117, 536-549, 1989.

Owe, M., de Jeu, R., and Holmes, T.: Multisensor historical climatology of satellite-derived global land surface moisture, J. Geophys. Res., 113, F01002, https://doi.org/10.1029/2007JF000769, 2008.

Peña-Arancibia, J. L., van Dijk, A. I., Renzullo, L. J., and Mulligan, M.: Evaluation of precipitation estimation accuracy in reanalyses, satellite products, and an ensemble method for regions in Australia and South and East Asia, J. Hydrometeorol., 14, 1323-1333, https://doi.org/10.1175/JHM-D-12-0132.1, 2013.

Quintana-Seguí, P., Le Moigne, P., Durand, Y., Martin, E., Habets, F., Baillon, M., Canellas, C., Franchisteguy, L., and Morel, S.: Analysis of near-surface atmospheric variables: validation of the SAFRAN analysis over France, J. Appl. Meteorol. Clim., 47, 92-107, https://doi.org/10.1175/2007JAMC1636.1, 2008.

Quintana-Seguí, P., Peral, M. C., Turco, M., Llasat, M.-C., and Martin, E.: Meteorological analysis systems in North-East Spain: validation of SAFRAN and SPAN, J. Environ. Inform., 27, 116130, https://doi.org/10.3808/jei.201600335, 2016.

Quintana-Seguí, P., Turco, M., Herrera, S., and Miguez-Macho, G.: Validation of a new SAFRAN-based gridded precipitation product for Spain and comparisons to Spain02 and ERA-Interim, Hydrol. Earth Syst. Sci., 21, 2187-2201, https://doi.org/10.5194/hess-21-2187-2017, 2017.

Ruiz, J. M.: Desarrollo de un modelo hidrológico conceptual distribuido de simulación continua integrado con un sistema de información geográfica (Development of a continuous distributed conceptual hydrological model integrated in a geographic information system), PhD Thesis, ETS Ingenieros de Caminos, Canales y Puertos, Universidad Politécnica de Valencia, Spain, 1998.

Seyyedi, H., Anagnostou, E. N., Kirstetter, P. E., Maggioni, V., Hong, Y., and Gourley, J. J.: Incorporating surface soil moisture information in error modeling of TRMM passive Microwave rainfall, IEEE T. Geosci. Remote, 52, 6226-6240, 2014. 
Sorooshian, S., Hsu, K. L., Gao, X., Gupta, H. V., Imam, B., and Braithwaite, D.: Evaluation of PERSIANN system satellitebased estimates of tropical rainfall, B. Am. Meteorol. Soc., 81, 2035-2046, 2000.

Stephens, G. L. and Kummerow, C. D.: The remote sensing of clouds and precipitation from space: a review, J. Atmos. Sci., 64, 3742-3765, 2007.

Taillardat, M., Mestre, O., Zamo, M., and Naveau, P.: Calibrated ensemble forecasts using quantile regression forests and ensemble model output statistics, Mon. Weather Rev., 144, 2375-2393, 2016.

Teo, C. K. and Grimes, D. I.: Stochastic modelling of rainfall from satellite data, J. Hydrol., 346, 33-50, https://doi.org/10.1016/j.jhydrol.2007.08.014, 2007.

Vidal, J. P., Martin, E., Franchistéguy, L., Baillon, M., and Soubeyroux, J. M.: A 50 year high-resolution atmospheric reanalysis over France with the Safran system, Int. J. Climatol., 30, 16271644, https://doi.org/10.1002/joc.2003, 2010.
Wagner, W., Dorigo, W., de Jeu, R., Fernandez, D., Benveniste, J., Haas, E., and Ertl, M.: Fusion of active and passive microwave observations to create an essential climate variable data record on soil moisture, in: ISPRS Annals of the Photogrammetry, Remote Sensing and Spatial Information Sciences, 25 August-1 September 2012, Melbourne, Australia, 315-321, 2012.

Weedon, G. P., Balsamo, G., Bellouin, N., Gomes, S., Best, M. J., and Viterbo, P.: The WFDEI meteorological forcing data set: WATCH forcing data methodology applied to ERA-Interim reanalysis data, Water Resour. Res., 50, 7505-7514, 2014.

Yenigun, K. and Ecer, R.: Overlay mapping trend analysis technique and its application in Euphrates Basin, Turkey, Meteorol. Appl., 20, 427-438, 2013.

Zimmermann, A., Francke, T., and Elsenbeer, H.: Forests and erosion: insights from a study of suspended-sediment dynamics in an overland flow-prone rainforest catchment, J. Hydrol., 428, 170-181, 2012. 